Article

\title{
Prognostic Factors in Merkel Cell Carcinoma: A Retrospective Single-Center Study in 90 Patients
}

\author{
Marco Rastrelli ${ }^{1,+}$, Beatrice Ferrazzi ${ }^{2,+}$, Francesco Cavallin ${ }^{3}$, Vanna Chiarion Sileni ${ }^{4}$, \\ Jacopo Pigozzo ${ }^{4}$, Alessio Fabozzi ${ }^{4}$ (D), Saveria Tropea ${ }^{1}$, Antonella Vecchiato ${ }^{1}$, Alessandra Costa ${ }^{1}$, \\ Alessandro Parisi ${ }^{5}$, Carlo Riccardo Rossi ${ }^{1,6}$, Paolo Del Fiore ${ }^{1}$ and Mauro Alaibac ${ }^{\text {,* }}$ \\ 1 Surgical Oncology Unit, Veneto Institute of Oncology IOV-IRCCS, 35121 Padua, Italy; \\ marco.rastrelli@iov.veneto.it (M.R.); saveria.tropea@iov.veneto.it (S.T.); \\ antonella.vecchiato@iov.veneto.it (A.V.); alessandra.costa@iov.veneto.it (A.C.); \\ paolo.delfiore@iov.veneto.it (P.D.F.) \\ 2 Dermatology Unit and Pathology Unit, Department of Medicine (DIMED), University of Padua, \\ 35121 Padua, Italy; ferrazzi.beatrice@gmail.com \\ 3 Independent Statistician, 35121 Solagna, Italy; cescocava@libero.it \\ 4 Melanoma and Esophagus Oncology Unit, Veneto Institute of Oncology IOV-IRCCS, 35121 Padua, Italy; \\ vanna.chiarion@iov.veneto.it (V.C.S.); jacopo.pigozzo@iov.veneto.it (J.P.); alessio.fabozzi@iov.veneto.it (A.F.) \\ 5 Radiotherapy Unit, Veneto Institute of Oncology, IOV-IRCCS, 35121 Padua, Italy; \\ alessandro.parisi@iov.veneto.it \\ 6 Department of Surgery, Oncology and Gastroenterology, University of Padua, 35121 Padua, Italy; \\ carlor.rossi@unipd.it \\ 7 Dermatology Unit, Department of Medicine (DIMED), University of Padova, 35128 Padua, Italy \\ * Correspondence: mauro.alaibac@unipd.it; Tel.: +39-049-821-2901 \\ + These authors contributed equally to the work.
}

Received: 6 August 2018; Accepted: 21 September 2018; Published: 24 September 2018 updates

\begin{abstract}
Merkel Cell Carcinoma (MCC) is a rare but highly aggressive neuroendocrine neoplasm of the skin. This study aimed at describing characteristics, treatment, and prognosis of a series of consecutive cases of MCC patients, in order to contribute to the investigation of this rare malignancy and provide better patient care. This is a retrospective cohort study including all 90 patients diagnosed and/or treated for MCC between 1991 and 2018 at the Veneto Institute of Oncology in Padua (Italy). Patient and tumor characteristics, treatment, and immunohistochemical data were extracted from a prospectively collected local database. There were 68 primary $(76 \%)$ and 22 non-primary (15 occult primary, three metastatic, four recurrence) tumors (24\%). CK20 expression was associated with reduced overall (HR 2.92, 95\% CI 1.04-8.16) and disease-specific (HR 4.62, 95\% CI 1.31-16.28) survival. Immunomodulatory regimens for treatment of other comorbidities were associated with reduced disease-specific ((HR 2.15, 95\% CI 1.06-4.36) and recurrence-free (HR 3.08, 95\% CI 1.44-6.57) survival. Iatrogenic immunomodulation resulted as the main factor associated with impaired prognosis. Lack of CK20 expression was associated with better survival.
\end{abstract}

Keywords: Merkel cell carcinoma; neuroendocrine neoplasm; skin neoplasm; survival; CK20 expression; immunomodulatory drugs

\section{Introduction}

Merkel Cell Carcinoma (MCC) is a rare neuroendocrine neoplasm of the skin [1]. It was first described by Toker in 1972 as trabecular carcinoma of the skin [2] and then renamed in its current form because of common features with Merkel cells [3]. Consequently, Merkel cells were suggested to be the source of MCC, on the basis of both the ultrastructural finding of neuroendocrine granules and 
the immunohistochemical expression of CK20 (Figure 1) and CD56 [4-6]. However, the exact tumor genesis is still unclear $[7,8]$.

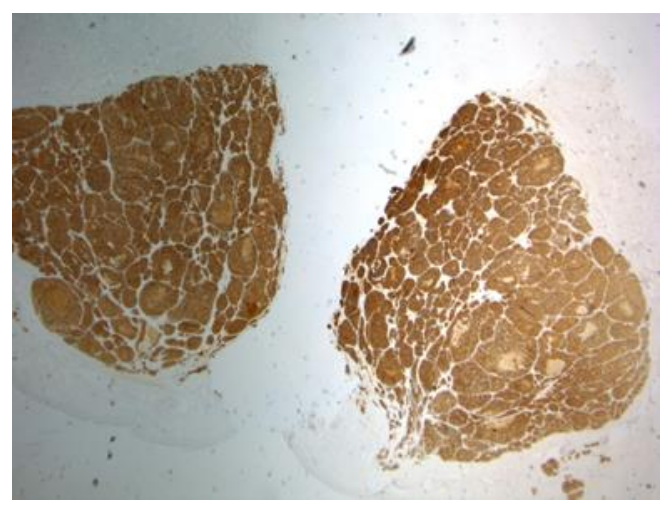

Figure 1. CK20 staining of a case of MMC.

The incidence rate of MCC varies across different regions of the world (from 0.13 in Europe to 1.6 per 100,000 in Australia) [9]. MCC is usually asymptomatic with rapid expansion and preferential localization on head, neck and arms in skin exposed to sunlight [3,9]. Risk factors include older age, immunosuppression, exposure to ultraviolet (UV) radiation, fair skin, and previous malignancies [1,9]. The immune system has an essential role in preventing the development of MCC, as suggested by the highest incidence of MCC in patients with hematological malignancies, HIV infection, organ transplantation, and in those treated with immunosuppressive agents [10-12].

Because of the strong connection between the disease and immune suppression, a possible viral etiology of the disease was suspected. In 2008 Feng and Shuda, isolated an unknown polyomavirus in MCC's tumor cells and named it Merkel Cell Polyomavirus (MCPyV). The virus is clonally integrated in $80 \%$ of MCCs, suggesting its oncogenetic role in the pathogenesis of the neoplasm [13]. On the basis of the discovery of MCPyV, two different subtypes of MCC can be individuated: MCC MCPyV+, which has a better prognosis, and MCPyV-, related to sun exposure, which has the highest mutation rate and more aggressive behavior [14].

MCC is highly aggressive and is the second most common cause of skin cancer death after melanoma [9]. Treatment strategy includes surgery (wide excision) in patients with locoregional primary MCC, followed by complete lymph node dissection in clinical node-positive patients. Sentinel node biopsy concurrent with wide excision is recommended in all patients with primary disease. Radiotherapy can be offered as adjuvant treatment after surgery and as primary or palliative treatment for inoperable cases, while chemotherapy is usually reserved for metastatic disease. Over the last few years immunotherapy has offered new therapeutic strategies and has been used for treatment of advanced MCC in patients not responsive to chemotherapy or as first-line treatment in metastatic disease. [9,15].

This study aimed at describing the characteristics, treatment, and prognosis of a series of 90 consecutive cases of MCC presented at our Institute.

\section{Results}

\subsection{Patients}

The study included 90 patients (50 male and 40 female; median age: 69 years) with a diagnosis of MCC observed between December 1991 and January 2018. Patient characteristics are shown in Table 1. There were 68 primary ( $76 \%$ ) and 22 non-primary ( 15 occult primary, three metastatic, four recurrence) tumors $(24 \%)$. MCC was generally observed on the extremities $(63 \%)$, followed by the trunk/buttocks $(19 \%)$ and head /neck (18\%). 
Table 1. Patient characteristics.

\begin{tabular}{|c|c|c|c|c|}
\hline & & All Patients & Non-Primary Tumors & Primary Tumors \\
\hline & N Patients & 90 & 22 & 68 \\
\hline \multirow{8}{*}{ Demographics } & Age at diagnosis, years a & $69(61-78)$ & $69(61-79)$ & $66(62-73)$ \\
\hline & Sex: & & & \\
\hline & Female & $40(44)$ & $9(41)$ & $31(46)$ \\
\hline & Male & $50(56)$ & $13(59)$ & $37(54)$ \\
\hline & Familiarity ${ }^{b}$ : & & & \\
\hline & No & $35(39)$ & $7(32)$ & $28(41)$ \\
\hline & Yes & $13(14)$ & $4(18)$ & $9(13)$ \\
\hline & Information not available & $42(47)$ & $11(50)$ & $31(46)$ \\
\hline \multirow{12}{*}{ Merkel cell Carcinoma } & Tumor size: & & & \\
\hline & $\leq 2 \mathrm{~cm}$ & $19(21)$ & 0 & $19(28)$ \\
\hline & $>2 \mathrm{~cm}$ & $71(79)$ & $22(100)$ & $49(72)$ \\
\hline & Anatomic location ${ }^{c}$ : & & & \\
\hline & Head/neck & $15(20)$ & $0(0)$ & $15(22)$ \\
\hline & Extremities & $44(59)$ & $5(71)$ & $39(57)$ \\
\hline & Trunk/buttocks & $16(21)$ & $2(29)$ & $14(21)$ \\
\hline & Tumor stage [16]: & & & \\
\hline & I & $19(21)$ & 0 & $19(28)$ \\
\hline & II & $19(21)$ & $2(9)$ & $17(25)$ \\
\hline & III & $47(52)$ & $17(77)$ & $30(44)$ \\
\hline & IV & $5(6)$ & $3(14)$ & $2(3)$ \\
\hline \multirow{9}{*}{ Comorbidity } & $\begin{array}{l}\text { Age-adjusted Charlson } \\
\text { comorbidity index }\end{array}$ & $3(2-4)$ & $3(2-4)$ & $4(2-5)$ \\
\hline & Neoplastic comorbidity: & & & \\
\hline & No & $70(78)$ & $19(86)$ & $51(75)$ \\
\hline & Yes & $20(22)$ & $3(14)$ & $17(25)$ \\
\hline & Autoimmune comorbidity: & & & \\
\hline & No & $66(73)$ & $14(64)$ & $52(77)$ \\
\hline & Organ-specific & $7(8)$ & $2(9)$ & $5(7)$ \\
\hline & Systemic & $13(15)$ & $4(18)$ & $9(13)$ \\
\hline & Both & $4(4)$ & $2(9)$ & $2(3)$ \\
\hline \multirow{6}{*}{ Drugs } & Immunomodulatory: & & & \\
\hline & No & $71(81)$ & $19(86)$ & $54(79)$ \\
\hline & Yes & $17(19)$ & $3(14)$ & $14(21)$ \\
\hline & Statins: ${ }^{\mathrm{d}}$ & & & \\
\hline & No & $81(90)$ & $19(86)$ & $62(91)$ \\
\hline & Yes & $9(10)$ & $3(14)$ & $6(9)$ \\
\hline \multirow{5}{*}{ Immunohistochemistry } & $\begin{array}{l}\text { Immunohistochemistry } \\
\text { availability, N patients }\end{array}$ & 62 & 11 & 51 \\
\hline & CK20: expression & $45(73)$ & $9(82)$ & $36(71)$ \\
\hline & NSE: expression & $15(24)$ & $2(18)$ & $13(25)$ \\
\hline & Synaptophysin: expression & $47(76)$ & $9(82)$ & $38(75)$ \\
\hline & Chromogranin: expression & $41(66)$ & $6(55)$ & $35(69)$ \\
\hline
\end{tabular}

Data expressed as $\mathrm{n}(\%)$ or ${ }^{\mathrm{a}}$ median (IQR). ${ }^{\mathrm{b}}$ Familiarity: the patient had a parent and/or sister and/or brother affected by neoplasm. ${ }^{c}$ information regarding 75 patients, patients with unknown primaries are excluded. ${ }^{\mathrm{d}}$ Patients receiving only statins for the treatment of other comorbidities.

\subsection{Treatment}

Surgical treatment and chemo-radiotherapy are shown in Figure 2. Primary surgical treatment was WE in 55 patients and CLND in 12. Seven patients underwent other surgical treatments (seven had wide resection), while the information was unclear in 16 patients who were treated in other hospitals. 
Following SNB, CLND identified median one positive lymph node (IQR 0-9). CLND was also performed in five patients with a negative SLN (median three positive lymph nodes, IQR 0-5). Among 46 patients who underwent CLND, extra capsular spread (ECS) was present in 20 (43\%) patients and absent in $26(57 \%)$ patients. Radiotherapy was administered to $32(36 \%)$ patients (29 adjuvant, one neoadjuvant, two metastatic). Chemotherapy was administered to $33(37 \%)$ patients (12 adjuvant, 21 metastatic).

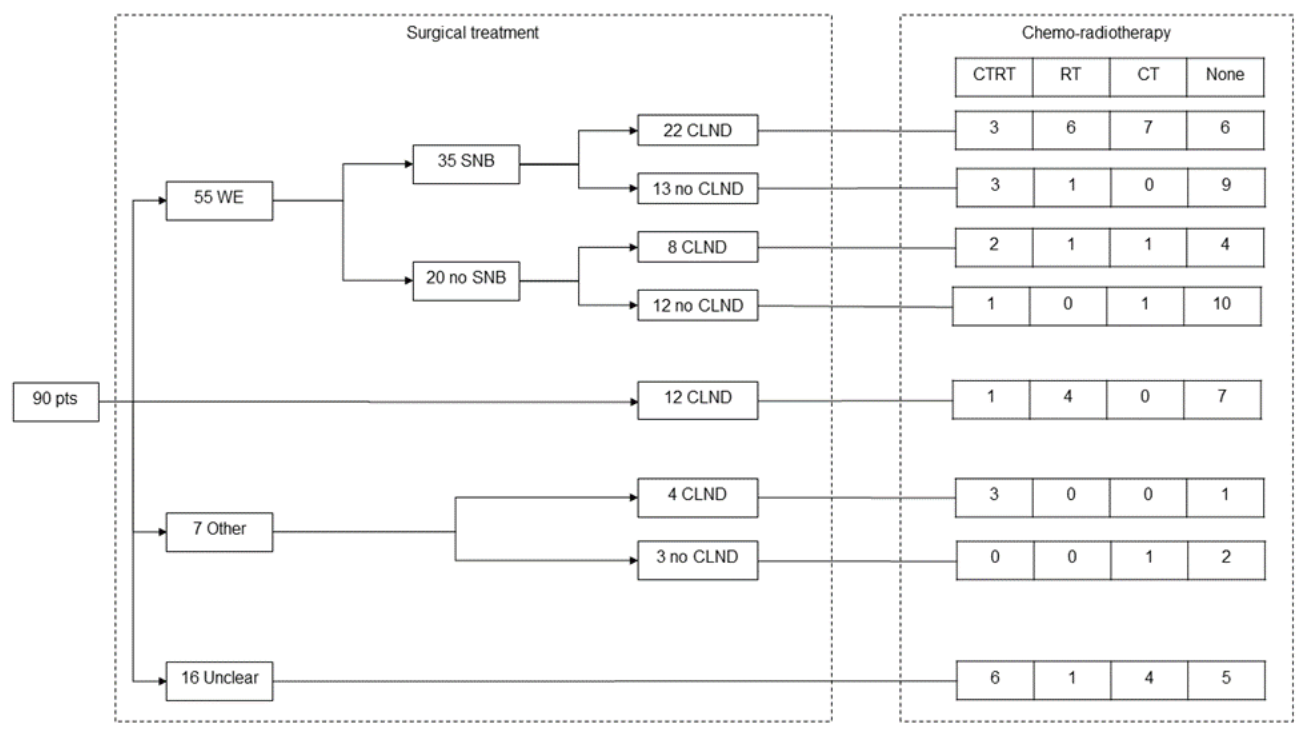

Figure 2. Surgical treatment and chemo-radiotherapy.

\subsection{Survival in Patients with Tumor Stage I-III}

Median follow-up was 29 months (IQR 13-61). Five-year overall survival was 53\% in patients with primary tumor and $41 \%$ in those with non-primary tumors $(p=0.78)$, while the five-year disease-specific survival was $58 \%$ in patients with primary tumors and $54 \%$ in those with non-primary tumors $(p=0.50)$ (Figure 3). Univariate analyses of overall survival and disease-specific survival are shown in Table 2. Impaired overall survival was associated with age-adjusted Charlson comorbidity index (HR 1.22, 95\% CI 1.01-1.49; $p=0.04$ ) and CK20 expression (HR 2.82, 95\% CI 1.01-7.93; $p=0.04$ ). Impaired disease-specific survival was associated with CK20 expression (HR 4.46, 95\% CI 1.26-15.82; $p=0.02$ ).
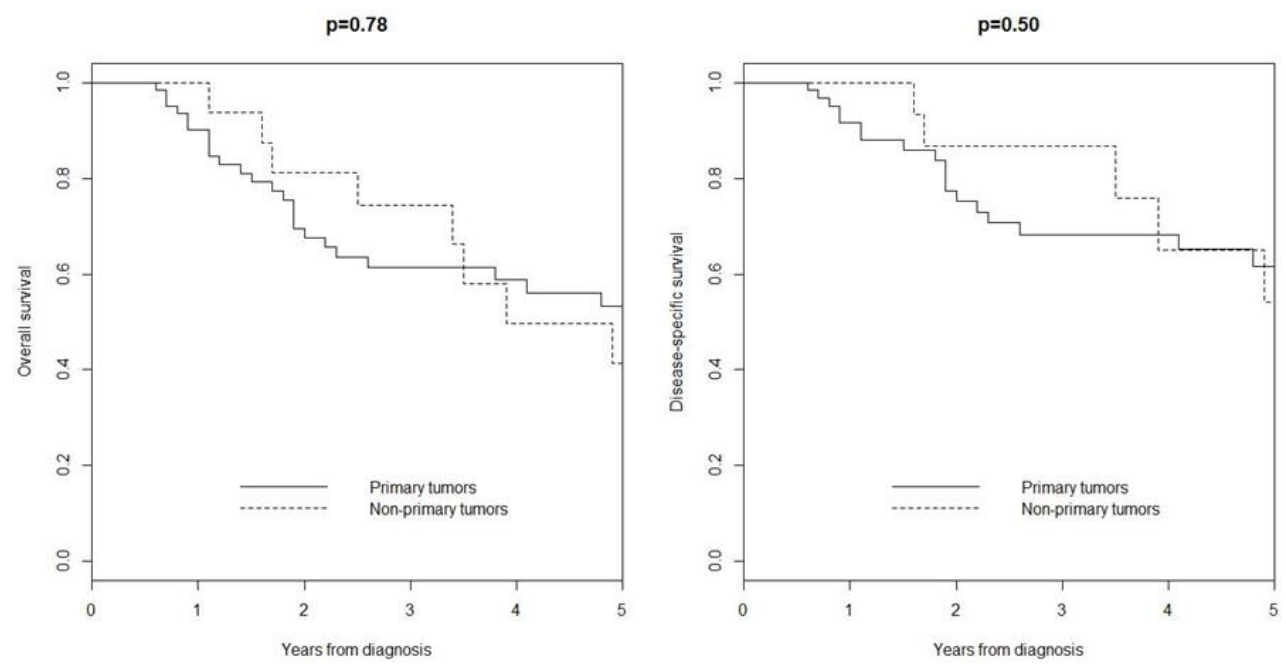

Figure 3. Overall survival and disease-specific survival in patients with tumor stage I-III. 
Table 2. Univariate analysis of overall survival and disease-specific survival in patients with tumor stage I-III.

\begin{tabular}{|c|c|c|c|c|}
\hline \multirow{2}{*}{ Patient Characteristics } & \multicolumn{2}{|c|}{ Overall Survival } & \multicolumn{2}{|c|}{ Disease-Specific Survival } \\
\hline & HR $(95 \%$ CI $)$ & $p$-Value & HR $(95 \%$ CI $)$ & $p$-Value \\
\hline Primary vs. non primary tumor & $1.10(0.54-2.30)$ & 0.78 & $1.41(0.53-3.742)$ & 0.49 \\
\hline Age at diagnosis & $1.02(0.99-1.05)$ & 0.17 & $1.01(0.97-1.04)$ & 0.62 \\
\hline Male vs. female & $1.29(0.68-2.45)$ & 0.43 & $1.79(0.79-4.02)$ & 0.16 \\
\hline Anatomic location: & & & & \\
\hline Head/neck vs. extremities & $1.34(0.59-3.19)$ & 0.46 & $1.99(0.78-5.11)$ & 0.15 \\
\hline Trunk/buttocks vs. extremities & $1.22(0.52-2.83)$ & 0.64 & $1.23(0.41-3.70)$ & 0.71 \\
\hline Tumor size: $>2$ cm vs. $\leq 2 \mathrm{~cm}$ & $1.60(0.62-4.10)$ & 0.33 & $1.37(0.47-3.97)$ & 0.57 \\
\hline Tumor stage: III vs. I-II & $1.56(0.82-2.95)$ & 0.18 & $2.06(0.91-4.69)$ & 0.08 \\
\hline Age-adjusted Charlson comorbidity index & $1.22(1.00-1.49)$ & 0.04 & $1.23(0.97-1.56)$ & 0.09 \\
\hline Neoplastic comorbidity: yes vs. no & $0.79(0.35-1.80)$ & 0.58 & $0.92(0.35-2.45)$ & 0.87 \\
\hline Autoimmune comorbidity: yes vs. no & $1.29(0.60-2.76)$ & 0.51 & $1.44(0.60-3.46)$ & 0.42 \\
\hline Immunomodulatory drugs: yes vs. no & $1.13(0.47-2.70)$ & 0.79 & $1.42(0.53-3.77)$ & 0.49 \\
\hline CK20: expression vs. absence ${ }^{a}$ & $2.82(1.01-7.93)$ & 0.04 & $4.46(1.26-15.82)$ & 0.02 \\
\hline NSE: expression vs. absence ${ }^{a}$ & $0.60(0.20-1.77)$ & 0.35 & $0.71(0.24-2.14)$ & 0.55 \\
\hline Synaptophysin: expression vs. absence ${ }^{a}$ & $2.19(0.74-6.52)$ & 0.16 & $1.84(0.61-5.56)$ & 0.28 \\
\hline Chromogranin: expression vs. absence ${ }^{a}$ & $0.74(0.31-1.75)$ & 0.49 & $0.93(0.35-2.44)$ & 0.89 \\
\hline Radiotherapy: yes vs. no & $0.87(0.45-1.70)$ & 0.68 & $1.61(0.75-3.85)$ & 0.22 \\
\hline
\end{tabular}

${ }^{\mathrm{a}}$ Information available in 62 patients.

SLN was positive in 15 patients and negative in 14 patients among those with primary tumor who received SNB concurrent with WE. Positive SLN seemed to be associated with impaired overall survival with respect to negative SLN (HR 4.49, 95\% CI 0.87-23.27; $p=0.07$ ). Disease-specific survival overlapped with overall survival.

In 35 patients with primary tumor who underwent CLND, a non-significant association of ECS with impaired overall survival was observed (HR 2.54, 95\% CI 0.86-7.52; $p=0.09$ ) and impaired disease-specific survival (HR 3.09, 95\% CI 0.95-10.10; $p=0.06$ ). In the same subgroup, having three or more positive LNs at CLND was not associated with overall survival (HR 1.66, 95\% CI 0.59-4.71; $p=0.34$ ) or disease-specific survival (HR 2.34, 95\% CI 0.70-7.79; $p=0.17$ ) with respect to having two or fewer positive LNs at CLND.

\subsection{Recurrence among Patients with Primary Stage I-III MCC}

At the time of the analysis, 28 patients with diagnosis of primary MCC developed disease recurrence. Local recurrence was observed in 16 patients, in-transit metastases in 6, LN metastases in 15 and distant metastases in 13. Five-year recurrence-free survival was 39\% (Figure 4). Univariate analyses of recurrence-free survival are shown in Table 3. Impaired recurrence-free survival was associated with receiving immunomodulatory drugs (HR 2.72, 95\% CI 1.22-6.10; $p=0.01$ ) and radiotherapy (HR 2.72, 95\% CI 1.28-5.77; $p=0.009$ ).

Among the patients with primary tumor who received SNB concurrent with WE, positive SLN was not associated with recurrence-free survival (HR 1.11, 95\% CI 0.35-3.58; $p=0.86$ ).

Among the patients with primary tumor who underwent CLND, ECS was not associated with recurrence-free survival (HR 1.47, 95\% CI 0.56-3.81; $p=0.43$ ). In the same subgroup, having three or more positive LNs at CLND was not associated with recurrence-free survival (HR $1.88,95 \% \mathrm{CI}$ $0.68-5.18 ; p=0.23$ ) with respect to having two or fewer positive LNs at CLND. 


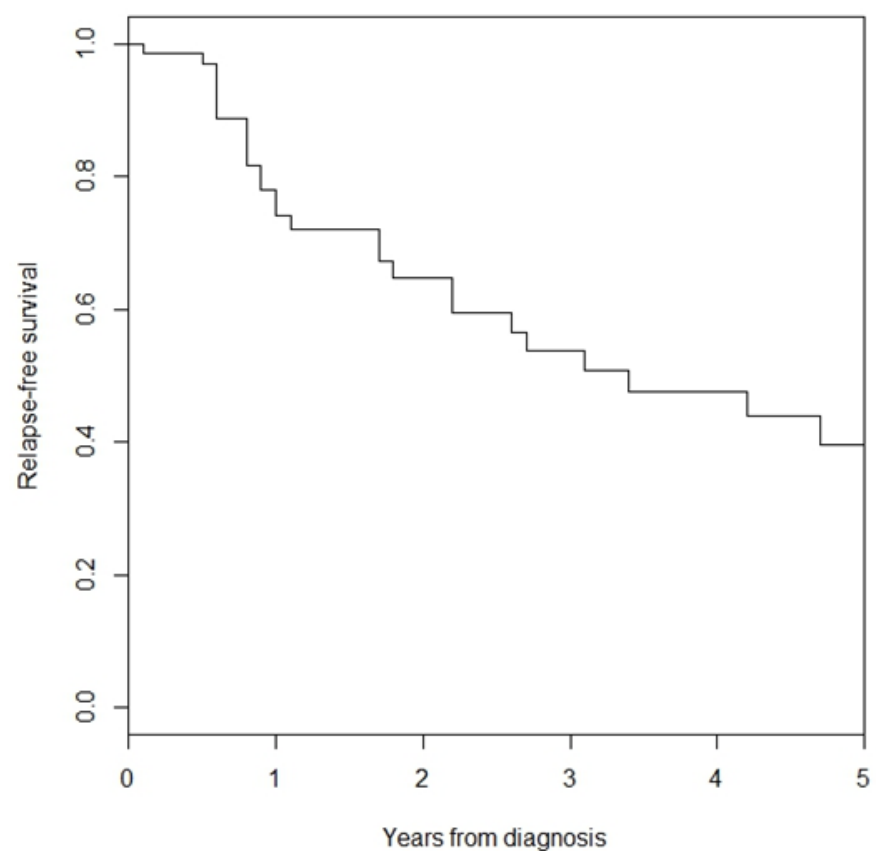

Figure 4. Recurrence -free survival among patients with primary stage I-III MCC.

Table 3. Factors associated with recurrence-free survival among patients with primary stage I-III tumor.

\begin{tabular}{ccc}
\hline \multirow{2}{*}{ Factors } & \multicolumn{2}{c}{ Recurrence-Free Survival } \\
\cline { 2 - 3 } & HR (95\% CI) & $p$-Value \\
\hline Age at diagnosis & $1.01(0.98-1.05)$ & 0.35 \\
Male vs. female & $0.81(0.39-1.72)$ & 0.59 \\
Anatomic location: & & \\
Head/neck vs. extremities & $1.10(0.41-2.94)$ & 0.85 \\
Trunk/buttocks vs. extremities & $1.00(0.13-7.53)$ & 0.99 \\
Tumor size: $>$ 2 cm vs. $\leq 2$ cm & $0.76(0.33-1.74)$ & 0.52 \\
Tumor stage III vs. I-II & $0.81(0.38-1.73)$ & 0.58 \\
Age-adjusted Charlson comorbidity index & $1.15(0.94-1.42)$ & 0.18 \\
Neoplastic comorbidity: yes vs. no & $0.85(0.34-2.10)$ & 0.72 \\
Autoimmune comorbidity: yes vs. no & $1.20(0.48-2.97)$ & 0.70 \\
Immunomodulatory drugs: yes vs. no & $2.72(1.22-6.10)$ & 0.01 \\
CK20: expression vs. absence ${ }^{\text {a }}$ & $1.43(0.54-3.78)$ & 0.48 \\
NSE: expression vs. absence ${ }^{\text {a }}$ & $0.68(0.25-1.88)$ & 0.46 \\
Synaptophysin: expression vs. absence ${ }^{\text {a }}$ & $1.96(0.70-5.45)$ & 0.20 \\
Chromogranin: expression vs. absence $^{\text {a }}$ & $1.15(0.44-2.99)$ & 0.78 \\
Radiotherapy: yes vs. no & $2.72(1.28-5.77)$ & 0.009 \\
\hline
\end{tabular}

${ }^{a}$ Information available in 51 patients.

\subsection{Comparison of MCC with Occult Primary and Primary MCC with Positive LNs}

Fifteen patients with MCC with occult primary were compared with 31 patients with primary MCC and positive LNs (Table 4). Tumor site was different between the two groups $(p<0.0001)$, with $73 \%$ of MCC with occult primary in trunk/buttocks and 77\% of primary MCC with positive LNs in extremities (Table 4). Neoplastic comorbidity was present in eight patients $(26 \%)$ with primary MCC and positive LNs, while it was absent in patients with MCC with occult primary ( $p=0.04$, Table 4$)$. Excluding three patients with tumor stage IV, five-year overall survival was $58 \%$ in patients with MCC with occult primary and $47 \%$ in those with primary MCC and positive LNs $(p=0.18)$, while five-year disease-specific survival was $64 \%$ in patients with MCC with occult primary and $48 \%$ in those with primary MCC and positive LNs ( $p=0.16)$. 
Table 4. Comparison of MCC with occult primary and primary MCC with positive LNs.

\begin{tabular}{|c|c|c|c|}
\hline & $\begin{array}{c}\text { MCC with } \\
\text { Occult Primary }\end{array}$ & $\begin{array}{c}\text { Primary MCC } \\
\text { with Positive LNs }\end{array}$ & $p$-Value \\
\hline $\mathrm{N}$ patients & 15 & 31 & - \\
\hline Age at diagnosis, years ${ }^{a}$ & $69(61-72)$ & $68(58-76)$ & 0.94 \\
\hline \multicolumn{4}{|l|}{ Sex: } \\
\hline Female & $7(47)$ & $10(32)$ & \multirow[t]{2}{*}{0.52} \\
\hline Male & $8(53)$ & $21(68)$ & \\
\hline \multicolumn{4}{|l|}{ Anatomic site: } \\
\hline Head/neck & $1(7)$ & $4(13)$ & \multirow{3}{*}{$<0.0001$} \\
\hline Extremities & $3(20)$ & $24(77)$ & \\
\hline Trunk/buttocks & $11(73)$ & $3(10)$ & \\
\hline \multicolumn{4}{|l|}{ Tumor stage: } \\
\hline III & $14(93)$ & $29(94)$ & \multirow[t]{2}{*}{0.99} \\
\hline IV & $1(7)$ & $2(6)$ & \\
\hline Age-adjusted Charlson comorbidity index ${ }^{a}$ & $3(2-3)$ & $3(2-5)$ & 0.39 \\
\hline \multicolumn{4}{|l|}{ Neoplastic comorbidity: } \\
\hline No & $15(100)$ & $23(74)$ & \multirow[t]{2}{*}{0.04} \\
\hline Yes & 0 & $8(26)$ & \\
\hline \multicolumn{4}{|l|}{ Autoimmune comorbidity: } \\
\hline No & $9(60)$ & $24(77)$ & \multirow{4}{*}{0.47} \\
\hline Organ-specific & $1(7)$ & $2(7)$ & \\
\hline Systemic & $3(20)$ & $4(13)$ & \\
\hline Both & $2(13)$ & $1(3)$ & \\
\hline \multicolumn{4}{|l|}{ Immunomodulatory drugs: } \\
\hline No & $10(67)$ & $24(77)$ & \multirow[t]{2}{*}{0.49} \\
\hline Yes & $5(33)$ & $7(23)$ & \\
\hline Immunohistochemistry availability, $\mathrm{N}$ patients & 9 & 22 & - \\
\hline CK20 & $7(78)$ & $17(77)$ & 0.99 \\
\hline NSE & $1(11)$ & $7(32)$ & 0.38 \\
\hline Synaptophysin & $8(89)$ & $16(73)$ & 0.64 \\
\hline Chromogranin & $5(56)$ & $16(73)$ & 0.42 \\
\hline Radiotherapy & $7(47)$ & $15(48)$ & 0.99 \\
\hline Chemotherapy & $5(33)$ & $14(45)$ & 0.53 \\
\hline
\end{tabular}

Data expressed as $\mathrm{n}(\%)$ or ${ }^{\mathrm{a}}$ median (IQR).

\section{Discussion}

Our study describes patient characteristics, treatment strategy and prognosis of a series of 90 consecutive cases of MCC.

In our study, about one-fifth of patients received immunomodulatory drugs for the treatment of other comorbidities. Immunomodulatory drugs included treatments for transplanted patients and patients affected by autoimmune diseases (i.e., steroids or immunosuppressive drugs such as cyclosporin). In our study, an immunomodulatory regimen was associated with reduced DFS, in agreement with previous data [17]. The iatrogenic systemic immune suppression caused by immunomodulatory drugs could explain the higher risk of recurrence in these patients. Immunosuppressed MCC patients have been demonstrated to have a worsened prognosis [18]. Modifying immunosuppressive regimens to decrease the cumulative immunosuppressive load may provide some prognostic advantages in these patients.

In this study, the lack of CK20 expression in immunohistochemistry was associated with better survival (both overall and disease-specific), while the other immunohistochemical markers (NSE, synaptophysin and chromogranin) did not show any relationship with the prognosis. CK20 is a cytokeratin polypeptide that is usually expressed in the gastric and intestinal epithelium, urothelium, and Merkel cells [19], whereas NSE, synaptophysin, and chromogranin are endocrine-related markers [20]. Since the early 1990s, immunohistochemical staining of CK20 has been performed to support the histopathological diagnosis in MCC [20], but it has also been evaluated as prognostic factor in other malignancies [21]. Our findings may suggest a prognostic role for CK20 expression also in MCC, although this finding should be confirmed in further studies with a larger sample size.

Our data confirm the association between survival and both tumor stage and comorbidity status in agreement with previous studies [22-24]. Although tumor size larger than $2 \mathrm{~cm}$ and the number of positive lymph nodes have already been associated with a worse prognosis [25], the limited 
sample size may have prevented us from showing this association in our study. Unexpectedly, survival was not different between patients with primary MCC and those with non-primary MCC, which is not consistent with previous published data [22]. This finding could be due to the inclusion of occult primary tumors among non-primary MCC, since previous studies suggested a better prognosis in patients with occult MCC if compared to those with primary MCC with positive LNs [26]. In our study, MCC was generally observed on the extremities in primary MCC with positive LNs, and trunk/buttocks in occult MCC. Neoplastic comorbidity was present in $25 \%$ of patients with primary MCC with positive LNs, while it was absent in patients with MCC with occult primary. These findings could be explained by a more efficient immune surveillance in patients with occult primary.

In our study, positive SLN seemed to be associated with impaired survival in patients with primary tumor, thus suggesting an indication for complete LN dissection and/or radiotherapy. However, there are conflicting results about the role of sentinel lymph node status on patient survival $[27,28]$. In addition, ECS in patients with primary tumor receiving CLND seemed to be associated with reduced survival, as previously reported [29]. It is noteworthy that almost half patients who underwent CLND had ECS.

Disease recurrence occurred in a considerable number of patients with primary MCC during follow-up, in agreement with previous studies [22]. Immunomodulatory regimens were associated with reduced recurrence-free survival along with reduced disease-specific survival. The failed immune surveillance of the cancer following the iatrogenic systemic immune suppression is probably the main factor for disease recurrence [18]. Radiotherapy was also associated with reduced recurrence-free survival, probably because it is generally performed in patients with advanced disease [3].

Our data confirms previously reported patient features associated with the development of MCC, notably older age, CK20 expression, synaptophysin expression and chromogranin expression $[9,19,20]$. In addition, $20 \%$ of patients had previous neoplasm and about $25 \%$ of patients had autoimmune comorbidities [30]. Finally, our investigation supports the view that radiotherapy is associated with a better regional control in MCC [31].

Our findings are consistent with the important role of immunomodulatory drugs in prognosis, thus confirming the necessity of a multidisciplinary approach in patient assessment.

The present study has however some limitations. First, the retrospective nature of the study limited the availability of data (i.e., immunohistochemistry). Second, this study reported a single-center experience, thus the generalizability of the findings is limited to similar settings. Third, the investigation included patients who had been treated using various modalities because of the long period of inclusion and different stages at diagnosis. Finally, it was not possible, using the data available, to perform a multivariate analysis.

\section{Materials and Methods}

\subsection{Study Design}

This is a retrospective cohort study including all patients diagnosed and/or treated for MCC between December 1991 and January 2018 at the Melanoma and Sarcoma Clinic of the Veneto Institute of Oncology in Padua (Italy). These institutions are level III referral center located in Northeastern Italy. Most patients are referred for diagnosis and/or first-line treatment, while some patients are referred for disease progression after being treated in local level II centers. The ethical committee gave the ethical approval Not. 4/2018 on 23 July 2018.

\subsection{Diagnosis and Treatment}

MCC was diagnosed according to histopathology and immunohistochemistry of the biopsy of the lesion. Tumor stage was defined according to the eighth version of the American Joint Committee on Cancer (AJCC) staging system, effective from January 2018 [16]. All diagnoses before January 2018 
were re-staged according to the last version of the staging system. A clinical example of a MCC is shown in Figure 5.

The surgical treatment included wide excision (WE) of the primary lesion, sentinel lymph node biopsy (SNB) and/or regional lymph nodes dissection. Patients with locoregional primary MCC underwent WE, followed by complete lymph node dissection in clinical node-positive patients. Sentinel node biopsy was performed concurrent with WE in patients with primary lesions. Patients with occult primary and clinical lymph node involvement received complete lymph node dissection (CLND). Immunotherapy and radio- and/or chemotherapy were offered based on tumor stage [15].

Radio-therapy was offered as adjuvant treatment in patients with operable disease, or as neo-adjuvant or palliative treatment for inoperable disease (i.e., recurrence or metastatic disease), while chemotherapy was usually reserved for metastatic disease. Immunotherapy has been used since 2017 in patients with metastatic disease who did not benefit from radio- and/or chemotherapy or as first line treatment in metastatic disease. Follow-up visits were performed every three to four months for the first three years, then every six months for up to five years and every year thereafter. A total-body CT scan was performed twice a year for the first five years. Disease progression included regional recurrences, in-transit metastases, lymph node metastases, and distant metastases.

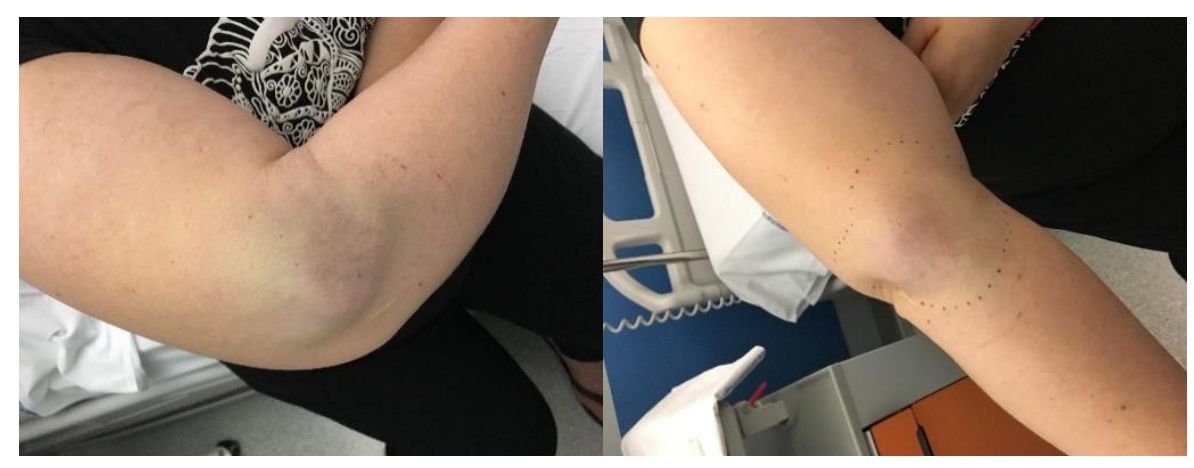

Figure 5. Patient with MCC. Lesion diameter $5 \times 6 \mathrm{~cm}$.

\subsection{Data Collection}

All data were extracted from a prospectively collected local database. Demographics included age at diagnosis, sex and familiarity, while tumor information included presentation, size, anatomic location, and stage. Comorbidity status was summarized using age-adjusted Charlson Comorbidity Index. The age adjusted Charlson Comorbidity Index is a prognostic classification used for patients who may be affected by comorbid conditions. It takes into consideration 19 comorbidity categories and patient age and each condition is given a score depending on the risk of death because of this specific condition. The overall score is the sum of the weighted scores for all comorbidity conditions. Patients with higher score have greater comorbidity condition and/or older age and score $>5$ implies a $100 \%$ mortality risk over one year.

Neoplastic comorbidity and autoimmune comorbidity were evaluated separately. Autoimmune comorbidity could be organ-specific (i.e., autoimmune thyroiditis) or systemic (i.e., rheumatoid arthritis). We considered the immunomodulatory drugs used for the treatment of patients' comorbidities such as long-term steroids, cyclosporine, and anti-rheumatic drugs. Immunohistochemistry data (the presence of CK20, NSE, Synaptophysin, and Chromogranin) were also retrieved. Information on treatment strategy included WE, SNB, CLND, immunotherapy, and radio- and/or chemotherapy. Follow-up information was extracted from scheduled visits. Overall survival was calculated from date of diagnosis to date of death or date of last visit. Disease-specific survival was calculated from date of diagnosis to date of disease-related death or date of last visit/disease-unrelated death. Recurrence-free survival was calculated in patients with primary MCC from date of diagnosis to date of recurrence or date of last visit/death. 


\subsection{Statistical Analysis}

Continuous data were expressed as median and interquartile range (IQR). Categorical data were compared between two groups using Fisher's exact test, while continuous data used Mann-Whitney test. Survival curves were calculated using the Kaplan-Meier method and compared with a log-rank test. The association between clinically relevant variables and survival (overall survival, disease-specific survival, and recurrence-free survival) was evaluated using Cox regression models, and expressed as the hazard ratio (HR) with a 95\% confidence interval $(95 \% \mathrm{CI})$. The association between survival and chemotherapy was not evaluated because chemotherapy was reserved for metastatic disease and thus was a proxy of metastatic disease rather than a possible risk factor for survival. The limited sample size and availability of immunohistochemistry data did not allow any meaningful multivariable analyses. All tests were two-sided and a $p$-value of less than 0.05 was considered statistically significant. Statistical analyses were performed using R 3.3 (R Foundation for Statistical Computing, Vienna, Austria) [32].

\section{Conclusions}

Our findings confirmed patient characteristics such as older age, CK20 expression, synaptophysin expression, and chromogranin expression. Previous neoplasm and autoimmune comorbidity were frequent. Immunosuppression was the main factor associated with impaired disease-free survival. The lack of CK20 expression in immunohistochemistry was associated with better survival. Our findings indicate the relevance of a multidisciplinary approach to patient assessment. Moreover, future multicenter trials are warranted, in particular with regard to the impact of the new immunotherapeutic approaches on overall survival in advanced stages [33].

Author Contributions: Conceptualization: M.A., M.R., V.C.S., and C.R.R.; Collection of medical follow-up data: J.P., A.P., and A.F.; Collection of surgical follow-up: S.T. and A.V.; Data Analysis: F.C.; Data Collection: B.F., P.D.F., and A.C.; Writing-Original Draft Preparation: B.F. and F.C. All authors read and approved the final manuscript.

Funding: This research received no external funding.

Acknowledgments: We thank Clara Benna (Department of Surgery Oncology and Gastroenterology-DISCOG, University of Padua, Italy) for the collection of data from the tissue bank.

Conflicts of Interest: The authors declare no conflict of interest.

$\begin{array}{ll}\text { Abbreviations } \\ \text { CI } & \text { confidence interval } \\ \text { CK } & \text { cytokeratin } \\ \text { CLND } & \text { complete lymph node dissection } \\ \text { ECS } & \text { extracapsular spread } \\ \text { HR } & \text { hazard ratio } \\ \text { LN } & \text { lymph node } \\ \text { MCC } & \text { Merkel cell carcinoma } \\ \text { SLN } & \text { sentinel lymph node } \\ \text { SNB } & \text { sentinel node biopsy }\end{array}$

\section{References}

1. Uchi, H. Merkel cell carcinoma: An update and immunotherapy. Front Oncol. 2018, 8, 48. [CrossRef] [PubMed]

2. Toker, C. Trabecular carcinoma of the skin. Arch. Dermatol. 1972, 105, 107-110.

3. Müller-Richter, U.D.A.; Gesierich, A.; Kübler, A.C.; Hartmann, S.; Brands, R.C. Merkel cell carcinoma of the head and neck: Recommendations for diagnostics and treatment. Ann. Surg. Oncol. 2017, 24, 3430-3437. [CrossRef] [PubMed]

4. Tang, C.K.; Toker, C. Trabecular carcinoma of the skin: An ultrastructural study. Cancer 1978, 42, $2311-2321$. [CrossRef] 
5. Pulitzer, M.P.; Amin, B.D.; Busam, K.J. Merkel cell carcinoma: review. Adv. Anat. Pathol. 2009, 16, 35-44. [CrossRef] [PubMed]

6. Gallego, R.; García-Caballero, T.; Fraga, M.; Beiras, A.; Forteza, J. Neural cell adhesion molecule immunoreactivity in Merkel cells and Merkel cell tumours. Virchows. Arch. 1995, 426, 317-321. [CrossRef] [PubMed]

7. Jankowski, M.; Kopinski, P.; Schwartz, R.; Czajkowski, R. Merkel cell carcinoma: Is this a true carcinoma? Exp. Dermatol. 2014, 23, 792-794. [CrossRef] [PubMed]

8. Sunshine, J.C.; Jahchan, N.S.; Sage, J.; Choi, J. Are there multiple cells of origin of Merkel cell carcinoma? Oncogene 2018, 37, 1409-1416. [CrossRef] [PubMed]

9. Schadendorf, D.; Lebbé, C.; Zur Hausen, A.; Avril, M.F.; Hariharan, S.; Bharmal, M.; Becker, J.C. Merkel cell carcinoma: Epidemiology, prognosis, therapy and unmet medical needs. Eur. J. Cancer 2017, 71, 53-69. [CrossRef] [PubMed]

10. Ziprin, P.; Smith, S.; Salerno, G.; Rosin, R.D. Two cases of Merkel cell tumour arising in patients with chronic lymphocytic leukaemia. Br. J. Dermatol. 2000, 142, 525-528. [CrossRef] [PubMed]

11. Engels, E.A.; Frisch, M.; Goedert, J.J.; Biggar, R.J.; Miller, R.W. Merkel cell carcinoma and HIV infection. Lancet 2002, 359, 497-498. [CrossRef]

12. Penn, I.; First, M.R. Merkel's cell carcinoma in organ recipients: Report of 41 cases. Transplantation 1999, 68, 1717-1721. [CrossRef] [PubMed]

13. Feng, H.; Shuda, M.; Chang, Y. Moore PS Clonal integration of a polyomavirus in human Merkel cell carcinoma. Science 2008, 319, 1096-1100. [CrossRef] [PubMed]

14. Goh, G.; Walradt, T.; Markarov, V.; Blom, A.; Riaz, N.; Doumani, R.; Stafstrom, K.; Moshiri, A.; Yelistratova, L.; Levinsohn, J.; et al. Mutational landscape of MCPyV-positive and MCPyV-negative Merkel cell carcinomas with implications for immunotherapy. Oncotarget 2016, 7, 3403-3415. [CrossRef] [PubMed]

15. Lebbe, C.; Becker, J.C.; Grob, J.J.; Malvehy, J.; Del Marmol, V.; Pehamberger, H.; Peris, K.; Saiag, P.; Middleton, M.R.; Bastholt, L.; et al. Diagnosis and treatment of Merkel cell carcinoma. European consensusbased interdisciplinary guideline. Eur. J. Cancer 2015, 51, 2396-2403. [CrossRef] [PubMed]

16. Amin, M.B.; Edge, S.; Greene, F.; Byrd, D.R.; Brookland, R.K.; Washington, M.K.; Gershenwald, J.E.; Compton, C.C.; Hess, K.R.; Sullivan, D.C.; et al. AJCC Cancer Staging Manual, 8th ed.; Springer: New York, NY, USA, 2017; pp. 549-562. ISBN 978-3-319-40617-6.

17. Chan, I.S.; Bhatia, S.; Kaufman, H.L.; Lipson, E.J. Immunotherapy for Merkel cell carcinoma: A turning point in patient care. J. Immunother. Cancer 2018, 6, 23. [CrossRef] [PubMed]

18. Paulson, K.G.; Iyer, J.G.; Blom, A.; Warton, E.M.; Sokil, M.; Yelistratova, L.; Schuman, L.; Nagase, K.; Bhatia, S.; Asgari, M.M.; et al. Systemic immune suppression predicts diminished Merkel cell carcinoma-specific survival independent of stage. J. Investig. Dermatol. 2013, 133, 642-646. [CrossRef] [PubMed]

19. Moll, R.; Lowe, A.; Laufer, J.; Franke, W.W. Cytokeratin 20 in human carcinomas: A new histodiagnostic marker detected by monoclonal antibodies. Am. J. Pathol. 1992, 140, 427-447. [PubMed]

20. Harms, P.W. Update on Merkel cell carcinoma. Clin. Lab. Med. 2017, 37, 485-501. [CrossRef] [PubMed]

21. Karantza, V. Keratins in health and cancer: More than mere epithelial cell markers. Oncogene 2011, 30, 127-138. [CrossRef] [PubMed]

22. Harms, K.L.; Healy, M.A.; Nghiem, P.; Sober, A.J.; Johnson, T.M.; Bichakjian, C.K.; Wong, S.L. Analysis of prognostic factors from 9387 Merkel cell carcinoma cases forms the basis for the new 8th edition AJCC staging system. Ann. Surg. Oncol. 2016, 23, 3564-3571. [CrossRef] [PubMed]

23. Austin, S.R.; Wong, Y.N.; Uzzo, R.G.; Beck, J.R.; Egleston, B.L. Why summary comorbidity measures such as the charlson comorbidity index and elixhauser score work. Med. Care. 2015, 53, e65-e72. [CrossRef] [PubMed]

24. Asgari, M.M.; Sokil, M.M.; Warton, E.M.; Iyer, J.; Paulson, K.G.; Nghiem, P. Effect of host, tumor, diagnostic, and treatment variables on outcomes in a large cohort with Merkel cell carcinoma. JAMA Dermatol. 2014, 150, 716-723. [CrossRef] [PubMed]

25. Iyer, J.G.; Storer, B.E.; Paulson, K.G.; Lemos, B.; Phillips, J.L.; Bichakjian, C.K.; Zeitouni, N.; Gershenwald, J.E.; Sondak, V.; Otley, C.C.; et al. Relationships among primary tumor size, number of involved nodes, and survival for 8044 cases of Merkel cell carcinoma. J. Am. Acad Dermatol. 2014, 70, 637-643. [CrossRef] [PubMed] 
26. Foote, M.; Veness, M.; Zarate, D.; Poulsen, M. Merkel cell carcinoma: The prognostic implications of an occult primary in stage IIIB (nodal) disease. J. Am. Acad Dermatol. 2012, 67, 395-399. [CrossRef] [PubMed]

27. Fritsch, V.A.; Camp, E.R.; Lentsch, E.J. Sentinel lymph node status in Merkel cell carcinoma of the head and neck: Not a predictor of survival. Head Neck. 2014, 36, 571-579. [CrossRef] [PubMed]

28. Servy, A.; Maubec, E.; Sugier, P.E.; Grange, F.; Mansard, S.; Lesimple, T.; Marinho, E.; Couturaud, B.; Girod, A.; Albert, S.; et al. Merkel cell carcinoma: Value of sentinel lymph-node status and adjuvant radiation therapy. Ann. Oncol. 2016, 27, 914-919. [CrossRef] [PubMed]

29. Mattavelli, I.; Patuzzo, R.; Torri, V.; Gallino, G.; Maurichi, A.; Lamera, M.; Valeri, B.; Bolzonaro, E.; Barbieri, C.; Tolomio, E.; et al. Prognostic factors in Merkelcell carcinoma patients undergoing sentinel node biopsy. Eur. J. Surg. Oncol. 2017, 43, 1536-1541. [CrossRef] [PubMed]

30. Becker, J.C.; Stang, A.; DeCaprio, J.A.; Cerroni, L.; Lebbé, C.; Veness, M.; Nghiem, P. Merkel cell carcinoma. Nat. Rev. Dis. Primers. 2017, 3, 17077. [CrossRef] [PubMed]

31. Kang, S.H.; Haydu, L.E.; Goh, R.Y.; Fogarty, G.B. Radiotherapy is associated with significant improvement in local and regional control in Merkel cell carcinoma. Radiat. Oncol. 2012, 7, 171. [CrossRef] [PubMed]

32. R Core Team. R: A Language and Environment for Statistical Computing; R Foundation for Statistical Computing: Vienna, Austria, 2016.

33. Nghiem, P.; Bhatia, S.; Brohl, A.S.; Hamid, O.; Mehnert, J.M.; Terheyden, P.; Shih, K.C.; Brownell, I.; Lebbé, C.; Lewis, C.D.; et al. Two-year efficacy and safety update from JAVELIN Merkel 200 part A: A registrational study of avelumab in metastatic Merkel cell carcinoma progressed on chemotherapy. J. Clin. Oncol. 2018, 36, 9507. [CrossRef]

(C) 2018 by the authors. Licensee MDPI, Basel, Switzerland. This article is an open access article distributed under the terms and conditions of the Creative Commons Attribution (CC BY) license (http://creativecommons.org/licenses/by/4.0/). 